\title{
The effect and clinical efficacy of lienal polypeptide injection combined with FOLFOX chemotherapy regimen in colon cancer patients
}

\author{
JUAN ZHOU ${ }^{1 *}$, GUOPING NIU $^{1 *}$, YUNFENG PEI $^{1}$, CHUNPING CAO $^{1}, \mathrm{CHEN} \mathrm{DING}^{1}$, \\ GUANGMING SUN ${ }^{1}$, JING GUO $^{1}$, YONG LIU ${ }^{2}$ and YANG YU ${ }^{2}$ \\ ${ }^{1}$ Clinical Laboratory and ${ }^{2}$ Department of Medical Oncology, Xuzhou Central Hospital, Xuzhou, Jiangsu 221000, P.R. China
}

Received June 2, 2016; Accepted August 19, 2016

DOI: $10.3892 / 01.2016 .5055$

\begin{abstract}
The aim was to investigate the clinical efficacy and immunomodulatory effect of lienal polypeptide injection combined with postoperative FOLFOX chemotherapy regimen in colon cancer patients. A total of 84 colon cancer patients were selected between January, 2014 and December, 2015. The selected patients were randomly divided into the observation (42 patients) and control (42 patients) groups. The observation group patients were treated with FOLFOX chemotherapy regimen combined with lienal polypeptide, whereas, the control group patients were treated with FOLFOX chemotherapeutic regimen only. After two cycles of treatment, Karnofsky performance scale (KPS) index, side effects or toxicity and the peripheral blood T-cell subset analyses in the two groups of patients were evaluated. The patients who received FOLFOX chemotherapeutic regimen combined with lienal polypeptide in the observation group showed significantly higher score of KPS than patients of the control group $(\mathrm{P}<0.05)$. No significant difference in the spectrum of side effects such as nausea, vomiting, neurotoxicity, liver and kidney dysfunction, oral mucosal inflammation were observed in the treatment groups. However, the incidence of bone marrow suppression was significantly lower in the observation group in comparison with the control group $(\mathrm{P}<0.05)$. Additionally, the $\mathrm{CD}^{+} \mathrm{T}$ cells were decreased in the observation group patients compared to the control group, while the ratio of $\mathrm{CD} 4^{+} \mathrm{T} / \mathrm{CD}^{+} \mathrm{T}\left(\mathrm{T}_{\mathrm{H}} / \mathrm{T}_{\mathrm{C}}\right)$ cells and the number of natural killer cells were higher in the observation group patients than the control group $(\mathrm{P}<0.05)$. In conclusion, the results suggest that, when the standard FOLFOX chemotheraputic regimen is combined with lienal polypeptide to treat
\end{abstract}

Correspondence to: Dr Yang Yu, Department of Medical Oncology, Xuzhou Central Hospital, 199 Jiefang Road, Xuzhou, Jiangsu 221000, P.R. China

E-mail: yuyangxz21@163.com

*Contributed equally

Key words: colon cancer, adjuvant chemotherapy, lienal polypeptide injection, Karnofsky performance scale score, toxicity, immune function colon cancer, it enhances the general well being of patients and strengthens the immune system in the combat against cancer.

\section{Introduction}

Non-communicable diseases contribute to $83 \%$ of deaths and of these $21 \%$ are due to cancer in China (1). Colon cancer is one of the most common types of cancer in many countries with an incidence of 1,360,000 cases and mortality of 694,000 individuals, but 3,544,000 cancer survivors worldwide (2). A recent estimate suggested that, China has an incidence of 253,000 cases and mortality rate of 139,000 cases of colon cancer and these rates show a rising trend (2). Currently, the comprehensive treatment is dominated by surgery followed by radiotherapy, chemotherapy and other adjuvant therapy. Surgical resection is the preferred method of treatment for colon cancer because of its effectiveness (3). However, in the majority of patients, surgery does not arrest the risk of relapse. Consequently, adjuvant chemotherapy to patients that have undergone surgery is an efficacious method for preventing relapse and metastasis and an improved prognosis in clinical settings (4).

A majority of patients were in the mid-late stage when initially diagnosed, while approximately $60-70 \%$ of patients require adjuvant chemotherapy after surgery. The 'FOLFOX4' program is one of the main chemotherapeutic regimens for patients having undergone surgery for colon cancer (5). FOLFOX4 contains the drugs oxaliplatin, leucovorin (LV), and 400 and $600 \mathrm{mg}^{2}$ fluorouracil. Oxaliplatin is a third generation platinum anticancer drug, which regards DNA as the target site where the platinum atoms and DNA strand forms interstrand and intrastrand crosslink, thereby blocking DNA replication and transcription. Oxaliplatin is also non-cross-resistant with cisplatin, thus producing a synergistic effect in combination with fluorouracil (6).

The National Comprehensive Cancer Network and other guidelines clearly suggest that, for stage III colon cancer patients after surgery, any of the following adjuvant chemotherapeutic regimens including the FOLFOX program, Xelox program, or 5-Fu/CF program should be used (7). However, for stage II colon cancer patients after surgery, no recommendation is available regarding the use of adjuvant therapy, whereas 
for high-risk stage II colon cancer patients after surgery, adjuvant chemotherapy is recommended only during conditions including T4 (stage IIB), histological grading (grade III or IV), vascular tumor thrombus, preoperative intestinal obstruction or perforation, lymph node detection number $<12$ or no clear resection margin $(8,9)$. The recommended duration of postoperative adjuvant chemotherapy was 6 months.

Lienal polypeptide injection is manufactured from healthy calf spleen extract and $1 \mathrm{ml}$ contains $4 \mathrm{mg}$ of polypeptide, $5 \mathrm{mg}$ of free amino acid, $1 \mathrm{mg}$ of nucleic acid, and not $<100 \mu \mathrm{g}$ of total sugar. Previously it was shown that, the administration of calf spleen extract significantly improved viscera index, phagocytosis index, NK cell killing activity, IgG level in serum and elevated peripheral blood leukocyte and lymphocyte counts in immunocompromised mice (10). Previous findings showed that, lienal polypeptide can function as an immune modulator and effectively enhanced the immunity of patients $(11,12)$.

The aim of the present study was to investigate the immunomodulatory effect and clinical efficacy of FOLFOX4 chemotherapeutic regimen combined with lienal polypeptide in colon cancer patients.

\section{Patients and methods}

Patients. In total, 84 pathologically confirmed patients who underwent surgery for colon cancer in the Department of Medical Oncology of Xuzhou Central Hospital (Jiangsu, China) from January, 2014 to December, 2015 were included for the study. Of the 84 patients, 56 were men and 28 women, with a median age of $52.8 \pm 6.8$ years. The patients of the present study were required to be pathologically diagnosed to have colon cancer, to be in stage II or III with high risk, to have routine blood, liver and kidney function tests and ECG performed, to have no contraindications for chemotherapy, expected to have survival for more $>3$ months and to be ready to receive chemotherapy four weeks after surgery. The patients used mandarin to communicate and had no severe cognitive impairment, and no history of psychiatric, alcohol and drug dependence. The clinicopathological characteristics of the two groups are shown in Table I.

The patients were randomly divided into the observation and control groups using the random number method. After four weeks of surgery, patients in the observation group (42 patients) received adjuvant FOLFOX4 chemotherapy combined with lienal polypeptide. The remaining 42 patients in the control group were administered only with FOLFOX4 adjuvant chemotherapeutic regimen.

The present study complied with the Declaration of Helsinki and was approved by the Ethics Committee of Central Hospital of Xuzhou. Written informed consent was obtained from all the patients.

Treatment of patients. The observation group patients received FOLFOX4 chemotherapeutic regimen, which consisted of L-OHP $85 \mathrm{mg} / \mathrm{m}^{2}$ intravenous infusion $2 \mathrm{~h}$ on day 1 , CF $200 \mathrm{mg} / \mathrm{m}^{2}$ intravenous infusion $2 \mathrm{~h}$ on days $1-2$, 5 -Fu $400 \mathrm{mg} / \mathrm{m}^{2}$ intravenous infusion on days $1-2$, and 5 -Fu $600 \mathrm{mg} / \mathrm{m}^{2}$ continuous trace chemotherapy pump infusion $22 \mathrm{~h}$ on days 1-2. A portable continuous intravenous infusion pump was used $(2 \mathrm{C} 1009 \mathrm{~K}, 5 \mathrm{ml} / \mathrm{h}$ velocity; Baxter, Deerfield,
Table I. Clinicopathological characteristics of the patients.

\begin{tabular}{lccc}
\hline Parameters & $\begin{array}{c}\text { Observation } \\
\text { group }\end{array}$ & $\begin{array}{c}\text { Control } \\
\text { group }\end{array}$ & P-value \\
\hline Gender & & & 0.81 \\
Male & 29 & 27 & \\
Female & 13 & 15 & \\
Age (years) & & & 0.59 \\
$\leq 40$ & 17 & 18 & \\
$41-50$ & 14 & 16 & \\
$51-60$ & 9 & 7 & \\
$\geq 60$ & $52.3 \pm 7.1$ & $53.1 \pm 6.6$ & \\
Median age & & & 0.78 \\
Pathological type & 38 & 37 & \\
Adenocarcinoma & 4 & 5 & \\
Non-adenocarcinoma & & & 0.87 \\
TNM staging & 12 & 14 & \\
II & 30 & 28 & \\
III & & & 0.49 \\
Pre-chemotherapy & & & \\
KPS score & 8 & 7 & \\
70 & 21 & 24 & \\
80 & 13 & 11 & \\
90 & $86.3 \pm 7.1$ & $85.6 \pm 6.9$ & \\
Median KPS score & & & \\
\hline
\end{tabular}

KPS, Karnofsky performance scale.

IL, USA). Concomitantly, the observation group patients were administered with $0.9 \%$ sodium chloride injection $500 \mathrm{ml}$ plus $10 \mathrm{ml}$ of lienal polypeptide (2/100 ml; Jilin Fengsheng Pharmaceutical Co. Ltd., Jilin, China) intravenous infusion once a day on days 1-10. The observation and control group patients were treated with FOLFOX4 regimen and FOLFOX4 combined with lienal polypeptide, respectively, for two cycles and each consisted of 14 days. Blood routine, liver and kidney functions were evaluated before and after chemotherapy of each cycle. Direct immunofluorescence labeling, whole blood hemolysis method and flow cytometry were used to detect lymphocytes and its subsets and these analyses were carried out 1-2 days before the first chemotherapy and 7-8 days after completion of the two cycles of chemotherapy.

Karnofsky performance scale (KPS) index. The KPS was used to determine the score (10-100) that was optimal to the patient's activity at a particular time-point to evaluate functional status of the patient after completion of two cycles of chemotherapeutic regimen.

Toxicity and side effects. Side effects such as nausea, vomiting, bone marrow suppression, neurotoxicity, the impairment of liver and renal function and oral mucosal inflammation after chemotherapy were recorded. The data were graded according to the grading standards for the toxicity of chemotherapeutic drugs (WHO). 
Table II. Incidence of side effects during chemotherapy.

\begin{tabular}{|c|c|c|c|c|c|c|c|}
\hline Groups & $\begin{array}{c}\text { No. of } \\
\text { patients }\end{array}$ & $\begin{array}{l}\text { Nausea, } \\
\text { vomitting, } \\
\text { n }(\%)\end{array}$ & $\begin{array}{l}\text { Bone marrow } \\
\text { suppression, } \\
\text { n }(\%)\end{array}$ & $\begin{array}{c}\text { Neurotoxicity, } \\
\text { n (\%) }\end{array}$ & $\begin{array}{l}\text { Liver function } \\
\text { impairment, } \\
\mathrm{n}(\%)\end{array}$ & $\begin{array}{l}\text { Kidney function } \\
\text { impairment, } \\
\text { n }(\%)\end{array}$ & $\begin{array}{c}\text { Oral mucosal } \\
\text { inflammation, } \\
n(\%)\end{array}$ \\
\hline Observation & 42 & $23(55)$ & $17(40)^{\mathrm{a}}$ & $18(43)$ & $2(5)$ & $0(0)$ & $5(12)$ \\
\hline Control & 42 & $28(67)$ & $29(69)$ & $20(48)$ & $3(7)$ & $1(2)$ & $6(14)$ \\
\hline Total & 84 & $51(61)$ & $46(55)$ & $38(45)$ & $5(6)$ & $1(1)$ & $11(13)$ \\
\hline
\end{tabular}

${ }^{\mathrm{a}} \mathrm{P}<0.05$ compared with the control group.

Table III. T-cell subsets between the observation and control groups before and after chemotherapy.

\begin{tabular}{lrrrr}
\hline \multirow{2}{*}{ T-cell subsets } & \multicolumn{2}{c}{ Observation group } & \multicolumn{2}{c}{ Control group } \\
\cline { 2 - 5 } & \multicolumn{1}{c}{ Before } & After & Before & After \\
\hline $\mathrm{CD} 4^{+} \mathrm{T}(\%)$ & $30.52 \pm 4.77$ & $31.24 \pm 4.51$ & $30.15 \pm 3.64$ & $30.52 \pm 4.26$ \\
$\mathrm{CD} 8^{+} \mathrm{T}(\%)$ & $28.26 \pm 4.10$ & $20.38 \pm 3.55^{\mathrm{a}, \mathrm{b}}$ & $28.48 \pm 3.98$ & $24.97 \pm 3.48$ \\
$\mathrm{CD} 4^{+} \mathrm{T} / \mathrm{CD} 8^{+} \mathrm{T}$ & $1.21 \pm 0.41$ & $1.73 \pm 2.99^{\mathrm{a}, \mathrm{b}}$ & $1.19 \pm 0.36$ & $1.41 \pm 3.08^{\mathrm{a}}$ \\
$\mathrm{NK}$ cells $(\%)$ & $9.16 \pm 3.72$ & $13.27 \pm 4.22^{\mathrm{a}, \mathrm{b}}$ & $9.27 \pm 4.19$ & $9.36 \pm 4.56$ \\
\hline
\end{tabular}

${ }^{a} \mathrm{P}<0.05$ compared with before chemotherapy. ${ }^{\mathrm{b}} \mathrm{P}<0.05$ compared with the control group.

Peripheral blood T-cell subset analysis. Prior to and after chemotherapy, peripheral blood T-cell subset analyses were carried out in the two groups of patients. The analyses included $\mathrm{CD}^{+}$lymphocytes $\left(\mathrm{T}_{\mathrm{H}}\right.$ lymphocytes), CD8 ${ }^{+}$lymphocyte ( $\mathrm{T}_{\mathrm{S}}$ lymphocytes), NK cells and the ratio of $\mathrm{CD} 4^{+} / \mathrm{CD}^{+}$.

Statistical analysis. SPSS 17.0 statistical software (Chicago, IL, USA) was used for the statistical analysis. The $\chi^{2}$ test was used to compare the KPS score and toxicity between two groups before and after chemotherapy. The independent samples t-test was used to compare the changes of $\mathrm{CD}^{+}$cells, $\mathrm{CD} 8^{+}$cells, $\mathrm{NK}$ cell activity and $\mathrm{CD} 4^{+} / \mathrm{CD}^{+}$of peripheral blood between two groups of patients before and after chemotherapy. $\mathrm{P}<0.05$ was considered statistically significant.

\section{Results}

KPS and side effects. The average KPS score of the observation group patients was significantly higher $(85.9 \pm 6.5)$ in comparison with the control group patients $(74.3 \pm 5.9)$ and this difference was statistically significant $(\mathrm{P}<0.05)$. The observed side effects in the two groups of patients were nausea, vomiting, bone marrow suppression, peripheral neurotoxicity (manifested as limb numbness, cold stimulation aggravation, and relief after withdrawal) and oral mucosal inflammation (grade I). These side effects were similarly distributed between the two groups, with the exception of bone marrow suppression. Bone marrow suppression was observed in only $40 \%$ of patients of the observation group, whereas, $69 \%$ of the control group patients showed bone marrow suppression $(\mathrm{P}<0.05$; Table II).
Effect of treatment on immune cells. Before chemotherapy, the number of $\mathrm{CD}^{+} \mathrm{T}$ cells, $\mathrm{CD}^{+} \mathrm{T}$ cells, NK cells and the ratio of $\mathrm{CD}^{+} / \mathrm{CD}^{+}$showed no significant difference between the two groups of patients $(\mathrm{P}>0.05)$.

Within each group, the level of peripheral blood $\mathrm{CD}^{+}$ $\mathrm{T}$ cells prior to chemotherapy was decreased in comparison with levels after chemotherapy, while the ratio of $\mathrm{CD}^{+} / \mathrm{CD}^{+}$ after chemotherapy was significantly increased $(\mathrm{P}<0.05)$ in comparison with the levels prior to chemotherapy. However, the observation group (FOLFOX + lienal polypeptide) showed a significantly higher ratio of $\mathrm{CD}^{+} / \mathrm{CD}^{+}$cells and $\mathrm{NK}$ cells compared to the control group $(\mathrm{P}<0.05$; Table III).

\section{Discussion}

In China, the incidence and mortality of colon cancer have increased significantly in the last 30 years, and the age of onset has also significantly advanced. The 5-year survival rate after colon cancer surgery in limitation period was $70 \%$, for stage III patients while it was 30-60 and 7\% for patients in advanced stage (13). Therefore, the timely detection of colon cancer, immediate surgical intervention, followed by postoperative adjuvant chemotherapy according to the postoperative pathology and staging, can effectively increase the survival rate and quality of life of patients (14).

Postoperative adjuvant chemotherapy affects biosynthesis and interferes with the normal metabolism of tumor cells, thereby inhibiting tumor cell proliferation. Subsequently, tumor cell killing is achieved. Thus, tumor relapse can be prevented and patient prognosis improved. The mechanism of adjuvant chemotherapy is dependent on chemotherapy and 
is able to regulate residual lesions after radical surgery (15). After surgical resection, the tumor cell load is small and the sensitivity of distantly metastasized tumor cells or local residual tumor cells to chemotherapy is high. Additionally, adjuvant chemotherapy is highly advantageous in the reduction of the formation of drug-resistant cancer cell clones (16). Thus, the combination of 5-Fu with LV chemotherapeutic regimen is considered as the classical treatment for colorectal cancer (17).

As an immune modulator, the lienal polypeptide has a dual regulatory effect on the immune system of the body. It corrects the disorder of immune function, thereby activating and enhancing non-specific immune function, promotes the maturation of $\mathrm{T}$ lymphocytes and sensitizes lymphocytes to improve the immune function of lymphocytes. The lienal polypeptide also induces the production of interferons that directly block viral protein synthesis and replication, and enhances the antigen presentation on the cell surface, promotes the cytotoxic activity of NK cells, and regulates lymphocyte and macrophage function, thus significantly improving the cell-mediated immune function. It also stimulates proliferation of bone marrow cells to produce a large number of white blood cells and enhances hematopoietic function (18). In addition, lienal polypeptide inhibits cell glycolysis without non-target cytotoxicity, in order that the high degree of glycolysis, an important feature of tumor cells, is reduced. This reduction results in the arrest of tumor cell metabolism and the prevention of tumor cells from entering into the $\mathrm{G}_{1}$ phase, thus producing an anticancer effect (19).

The present findings indicate that, in the observation group, the post-treatment KPS score was significantly higher than that of the control group, and myelosuppression was obviously reduced suggesting that, lienal polypeptide stimulated the proliferation of bone marrow cells and promoted the recovery of hematopoietic function of bone marrow. Additionally, the ratio of $\mathrm{CD}^{+} / \mathrm{CD}^{+}$and the number of $\mathrm{NK}$ cells were increased in the observation group patients compared to the control group and this revealed that lienal polypeptide significantly improved the immune function, and reduced the undesired effect of chemotherapy on the immune function along with improvement in the quality of life of the patients.

From the present study, it may be concluded that, for postoperative colon cancer patients, the combination of standard FOLFOX chemotherapy with lienal polypeptide can significantly alleviate bone marrow inhibition, enhances the immune function of patients and improves the quality of life and is worthy of further research and application.

\section{Acknowledgements}

The present study was carried out through the Xuzhou Municipal Science and Technology Information Bureau Project (XKQ058) and the Xuzhou City Center Hospital Dr Innovative Team Technology Project (XZB201304 and XZB201618).

\section{References}

1. World Health Organization: Non communicable disease country profiles, 2011. http://www.who.int/nmh/countries/chn_en.pdf. Accessed April 25, 2016.
2. Ferlay J,Soerjomataram I, Dikshit R,Eser S, Mathers C, Rebelo M, Parkin DM, Forman D and Bray F: GLOBOCAN 2012 v1.1, Cancer incidence and mortality worldwide: IARC CancerBase No. 11 (Internet). International Agency for Research on Cancer, Lyon, France, 2013. http://globocan.iarc.fr. Accessed April 14, 2016.

3. Sugarbaker PH: Surgery for recurrent colon cancer. Annintern Med 130: 239, 239-240, 1999.

4. Twelves C, Wong A, Nowacki MP, Abt M, Burris H III, Carrato A, Cassidy J, Cervantes A, Fagerberg J, Georgoulias V, et al: Capecitabine as adjuvant treatment for stage III colon cancer. N Engl J Med 352: 2696-2704, 2005.

5. André T, Boni C, Mounedji-Boudiaf L, Navarro M, Tabernero J, Hickish T, Topham C, Zaninelli M, Clingan P, Bridgewater $\mathrm{J}$, et al; Multicenter International Study of Oxaliplatin/5-Fluorouracil/Leucovorin in the Adjuvant Treatment of Colon Cancer (MOSAIC) Investigators: Oxaliplatin, fluorouracil, and leucovorin as adjuvant treatment for colon cancer. $\mathrm{N}$ Engl J Med 350: 2343-2351, 2004.

6. Yothers G, O'Connell MJ, Allegra CJ, Kuebler JP, Colangelo LH, Petrelli NJ and Wolmark N: Oxaliplatin as adjuvant therapy for colon cancer: Updated results of NSABP C-07 trial, including survival and subset analyses. J Clin Oncol 29: 3768-3774, 2011.

7. van Steenbergen LN, Elferink MA, Krijnen P, Lemmens VE, Siesling S, Rutten HJ, Richel DJ, Karim-Kos HE and Coebergh JW; Working Group Output of The Netherlands Cancer Registry: Improved survival of colon cancer due to improved treatment and detection: a nationwide populationbased study in The Netherlands 1989-2006. Ann Oncol 21: 2206-2212, 2010.

8. André T, Boni C, Navarro M, Tabernero J, Hickish T, Topham C, Bonetti A, Clingan P, Bridgewater J, Rivera F, et al: Improved overall survival with oxaliplatin, fluorouracil, and leucovorin as adjuvant treatment in stage II or III colon cancer in the MOSAIC trial. J Clin Oncol 27: 3109-3116, 2009.

9. Haller DG, Catalano PJ, Macdonald JS, O'Rourke MA, Frontiera MS, Jackson DV and Mayer RJ: Phase III study of fluorouracil, leucovorin, and levamisole in high-risk stage II and III colon cancer: final report of Intergroup 0089. J Clin Oncol 23: 8671-8678, 2005.

10. Olontseva OI, Moroz BB, Deshevoŭ IuB, Kalistratov GV and Shcherbova EN: Stimulation of the postradiation recovery of hematopoiesis in irradiated animals using a calf splenic extract. Radiobiologiia 29: 403-406, 1989 (In Russian).

11. Guo Y, Hu Q, Sun C, Gu B, Xu K and Xia G: Postoperative renormalization of C-reactive protein with adjuvant lienal polypeptide and its association with tumour recurrence in T1 clear cell renal cell carcinoma. J Int Med Res 44: 620-626, 2016.

12. Huang XE, Wang L, Ji ZQ, Liu MY, Qian T and Li L: Safety of lienal polypeptide injection combined with chemotherapy in treating patients with advanced cancer. Asian Pac J Cancer Prev 16: 7837-7841, 2015.

13. Elsaleh H, Joseph D, Grieu F, Zeps N, Spry N and Iacopetta B: Association of tumour site and sex with survival benefit from adjuvant chemotherapy in colorectal cancer. Lancet 355: $1745-1750,2000$.

14. Attard CL, Maroun JA, Alloul K, Grima DT and Bernard LM: Cost-effectiveness of oxaliplatin in the adjuvant treatment of colon cancer in Canada. Curr Oncol 17: 17-24, 2010.

15. Twelves C, Boyer M, Findlay M, Cassidy J, Weitzel C, Barker C, Osterwalder B, Jamieson C and Hieke K; Xeloda Colorectal Cancer Study Group: Capecitabine (Xeloda) improves medical resource use compared with 5-fluorouracil plus leucovorin in a phase III trial conducted in patients with advanced colorectal carcinoma. Eur J Cancer 37: 597-604, 2001.

16. Ayvaci MU, Shi J, Alagoz O and Lubner SJ: Cost-effectiveness of adjuvant FOLFOX and 5FU/LV chemotherapy for patients with stage II colon cancer. Med Decis Making 33: 521-532, 2013.

17. Moertel CG, Fleming TR, Macdonald JS, Haller DG, Laurie JA, Tangen CM, Ungerleider JS, Emerson WA, Tormey DC, Glick $\mathrm{JH}$, et al: Intergroup study of fluorouracil plus levamisole as adjuvant therapy for stage II/Dukes' B2 colon cancer. J Clin Oncol 13: 2936-2943, 1995.

18. Cheng M, Chen Y, Xiao W, Sun R and Tian Z: NK cell-based immunotherapy for malignant diseases. Cell Mol Immunol 10: 230-252, 2013.

19. Grivennikov SI, Greten FR and Karin M: Immunity, inflammation, and cancer. Cell 140: 883-899, 2010. 